\section{Comparing Concentration Levels and Emotional States of Children Using Electroencephalography during Horticultural and Nonhorticultural Activities}

\author{
Seon-Ok Kim and Ji-Eun Jeong \\ Department of Bio and Healing Convergence, Graduate School, Konkuk \\ University, Seoul 05029, Korea
}

Yun-Ah Oh and Ha-Ram Kim

Department of Animal and Plant Assisted Therapy, Graduate School of Agriculture and Animal Science, Konkuk University, Seoul 05029, Korea

Sin-Ae Park

Department of Bio and Healing Convergence, Graduate School, Konkuk University, Seoul, 05029, Korea; and Department of Systems Biotechnology, Konkuk Institute of Technology, Konkuk University, Seoul 05029, Korea

Additional index words. electroencephalography, gardening, horticultural therapy, semantic differential method

\begin{abstract}
This study aimed to compare the brain activity and emotional states of elementary school students during horticultural and nonhorticultural activities. A total of 30 participants with a mean age of $11.4 \pm 1.3$ years were included. This experiment was conducted at Konkuk University campus in Korea. Participants performed horticultural activities such as harvesting, planting, sowing seeds, and mixing soil. Nonhorticultural activities included playing with a ball, solving math problems, watching animation videos, folding paper, and reading a book. The study had a crossover experimental design. Brain activity of the prefrontal lobes was measured by electroencephalography during each activity for 3 minutes. On completion of each activity, participants answered a subjective emotion questionnaire using the semantic differential method (SDM). Results showed that relative theta (RT) power spectrum was significantly lower in both prefrontal lobes of participants when engaged in harvesting and reading a book. The relative mid beta (RMB) power spectrum was significantly higher in both prefrontal lobes when participants engaged in harvesting and playing with a ball. The ratio of the RMB power spectrum to the RT power spectrum reflects concentration. This ratio increased during harvesting activity, indicating that children's concentration also increased. The sensorimotor rhythm (SMR) from mid beta to theta (RSMT), another indicator of concentration, was significantly higher in the right prefrontal lobe during harvesting than during other activities. Furthermore, SDM results showed that the participants felt more natural and relaxed when performing horticultural activities than nonhorticultural activities. Horticultural activities may improve brain activity and psychological relaxation in children. Harvesting activity was most effective for improving children's concentration compared with nonhorticultural activities.
\end{abstract}

Horticultural activities have a variety of positive effects on humans. According to previous studies that measured metabolic equivalents (METs) when performing horti-

Received for publication 21 Oct. 2020. Accepted for publication 16 Dec. 2020.

Published online 22 January 2021.

This study was supported by the Konkuk University Researcher Fund in 2019.

S.-A.P. is the corresponding author. E-mail: sapark42@konkuk.ac.kr.

This is an open access article distributed under the CC BY-NC-ND license (https://creativecommons. org/licenses/by-nc-nd/4.0/).
Horticultural activities allow individuals to develop emotional stability and express emotions naturally through their participation with groups (Relf, 1992). Various horticultural activity programs have been effective for improving children's emotional intelligence, resilience, and self-efficacy (Lee et al., 2020; Oh et al., 2020). Additionally, the stress index values for interpersonal, school, personal, and family problems of the horticultural activity group were decreased (Lee et al., 2018a). Furthermore, it has recently been found that horticultural activity can improve serum tryptophan, kynurenine, and serotonin levels, which serve as biomakers for improved cognitive ability (Park et al., 2020). Another study reported that children exhibited increased brain activity and concentration when tasks were performed in spaces where plants were located (Kim et al., 2020).

Previous studies have reported that the visual stimulation of green plants has positive effects on the psychological and physiological aspects of individuals. Park et al. (2016) and Ikei et al. (2014) reported that viewing foliage plants induced psycho-physiological relaxing effects by reducing prefrontal cortical activity and increasing parasympathetic activity and emotional states. Park et al. (2017) found that tasks involving living plants induced more physiological relaxation because the concentration of oxy-hemoglobin in the prefrontal cortex of the participants was lowered. Additionally, Choi et al. (2016) reported that only $5 \%$ of the indoor green index could improve the heart rate variability and stimulate the autonomic nervous system as measured by electroencephalography (EEG), thus providing benefits to physiological stability. However, the subjects of these studies are limited to adults and the elderly, and few studies have involved children. Because the psychophysiological benefits of contact with plants may vary by age, this study aimed to identify the effects of horticultural activities on children's concentration and emotional states by measuring the EEG results.

\section{Materials and Methods}

Participants. This study involved 30 elementary school students between 10 and 13 years of age. In previous studies investigating the psycho-physiological effects of exposure to plants on humans, 30 participants were recruited as a single experimental group without a control group and showed significantly different results (Kim et al., 2020; Oh et al., 2019). Research information was posted on the bulletin boards of churches and apartments near Konkuk University to recruit participants. Students who wished to participate in the study were required to provide a consent form from their parents. The inclusion criterion was right-hand dominance because hand gestures between the dominant and nondominant hand differ during cortical activity (Tarkka and Hallett, 1990). Additionally, participants were required to fast for $2 \mathrm{~h}$ before the experiment. According 
to a study by Heckman et al. (2010), caffeine and other ingredients found naturally in various foods can stimulate the brain, thereby affecting data. Before the experiment, participants completed a questionnaire regarding their age, height, and weight. We also their measured body mass index (BMI) (ioi 353; Jawon Medical, Gyeongsan, South Korea). On completion of the study, participants received a \$20 incentive. This study was approved by the Institutional Review Board of Konkuk University (7001355-2017-10-HR-206).

Experimental condition. The experiment environment was created in a space $(180 \mathrm{~cm} \times 160 \mathrm{~cm})$ at the campus of Konkuk University in Seoul, South Korea. Ivory curtains were installed on both sides of the walls in front of the space, and white sheets were attached to the desks to minimize external stimuli during the experiment. The conditions of the experimental space were as follows: average temperature, $21.9 \pm 3.4{ }^{\circ} \mathrm{C}$; average relative humidity, $26.5 \pm 10.2 \%$; and average light intensity, $1184.7 \pm$ $1094.51 \mathrm{x}$

Experimental procedure. This study had a crossover experimental design (Kim et al., 2020; Oh et al., 2019). Before commencing the experiment, the participants rested for $1 \mathrm{~min}$ on chairs in the experimental space. Then, the participants randomly performed nonhorticultural and horticultural activities for $3 \mathrm{~min}$ each. After each activity, a questionnaire was conducted to record the subjective emotions of the participants, followed by 1 min of rest. A total of nine activities were performed be- fore the experiment was concluded (Fig. 1). The duration of the experiment per participant was $\approx 70 \mathrm{~min}$.

The activities were divided into four horticultural activities and five nonhorticultural activities (Table 1). Horticultural activities included harvesting red lettuce (Lactuca sativa L.) planted in garden boxes (Fig. 2A). The planting activity involved transferring peperomia (Peperomia argyreia) to a pot (Fig. 2B). The sowing activity involved sowing radish seeds (Raphanus sativus L.) in a sowing tray (Fig. 2C). Finally, the soil-mixing activity involved mixing horticultural soil (Fig. 2D).

In nonhorticultural activities, the ballplay activity involved bouncing a basketball in the experimental space (Fig. 2E). During the math activity, participants solved arithmetic problems excerpted from Korean national textbooks (Choi, 2015, 2017; Kang and Choi, 2015, 2017) appropriate for their grades (Fig. 2F). The video activity involved watching an animated television show called "Pokemon" (Fig. 2G). Before the paper-folding activity, the participants were taught to fold a paper airplane before the experiment. During the experiment, they were instructed to fold the paper in the manner in which they were taught (Fig. 2H). The reading activity involved reading Korean fairytales in an elementary school textbook (Fig. 2I).

Measurement. A wireless dry EEG device (Quick-20; Cognionics, San Diego, CA) was used to measure the participants' brain waves during both nonhorticultural and horticultural activities. This device minimizes the risk of electric shock compared to the wet electrode systems using electrolyte gel. Data were

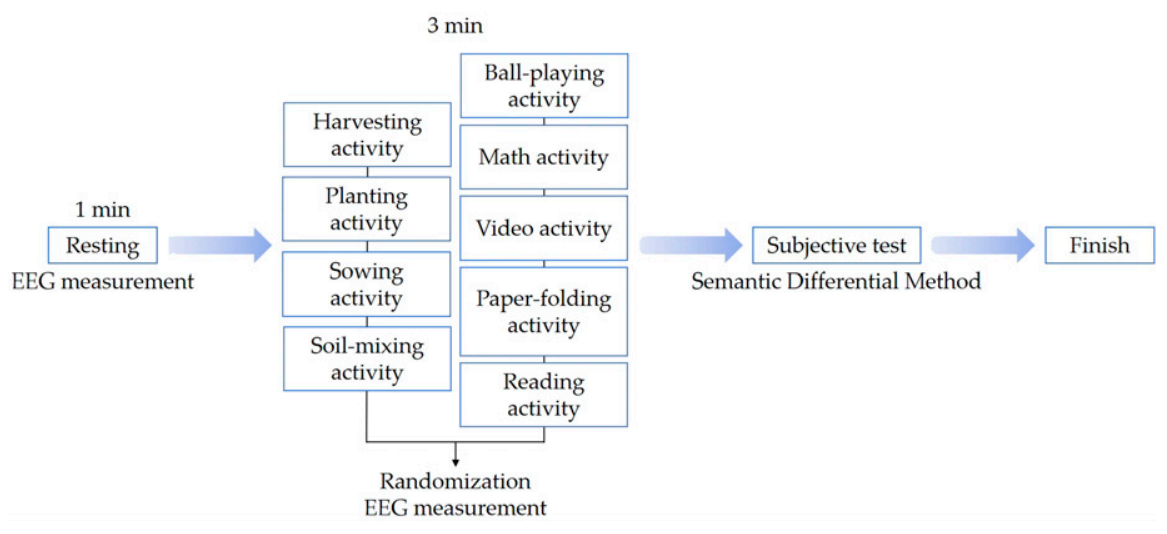

Fig. 1. Experimental protocol. EEG, electroencephalography. collected by amplifying and processing electrical signals measured via dry electrodes applied to the scalp. This device has been safety certified by the European Commission and the Federal Communications Commission (Kim et al., 2020).

The electrode application adhered to the international 10- to 20-electrode arrangement system (Jasper, 1958). The reference electrode was attached to the left earlobe (A1). The EEG results were measured using channels of the left prefrontal lobe (Fp1) and right prefrontal lobe (Fp2) involved in cognitive function (Fig. 3) (Miller and Cohen, 2001).

The SDM was used to evaluate the participants' psychological responses to each activity. SDM was developed by Osgood et al. (1957) to measure emotions using adjectives. The SDM is rated using a 13-point Likert scale and comprises three items: "comfortableuncomfortable," "natural-artificial," and "relaxed-awakening." The higher the score, the more positive the emotional state.

Data analysis. The EEG data were analyzed using Cognionics Data Acquisition (Cognionics). Brain waves from the cerebral cortex were classified as theta $(4-8 \mathrm{~Hz})$, alpha $(8-13 \mathrm{~Hz})$, beta $(13-30 \mathrm{~Hz})$, and gamma (30$50 \mathrm{~Hz}$ ) waves according to the frequency band (Sowndhararajan et al., 2015). The activation of each frequency band can be interpreted as having different meanings. For example, theta waves indicate shallow sleep, alpha waves refer to a stable condition, beta waves signify brain activity, and gamma waves show anxiety or excitement (Kim and Choi, 2001). This study analyzed the RT power spectrum, RMB power spectrum, and RSMT. The RT power spectrum was obtained by dividing the theta wave $(4-8 \mathrm{~Hz})$ by the total frequency $(4-50$ $\mathrm{Hz}$ ). The RMB power spectrum was obtained by dividing the mid beta wave $(15-20 \mathrm{~Hz})$ by the total frequency $(4-50 \mathrm{~Hz})$. Finally, the RSMT was obtained by dividing the SMR to mid beta $(12-20 \mathrm{~Hz})$ by the theta wave $(4-8$ Hz) (Sowndhararajan et al., 2015).

The results of the EEG and SDM for each activity were analyzed using IBM SPSS Statistics for Windows (version 25; IBM Corp., Armonk, NY). A one-way analysis of variance and Duncan's multiple range tests were used as the analysis methods, and the significance level was set at $P<0.05$. To analyze demographic information, Microsoft Excel (Microsoft Office 365 ProPlus; Microsoft, Redmond, WA) was used to determine the descriptive statistics.

Table 1. Description of activities.

\begin{tabular}{lll}
\hline Division & \multicolumn{1}{c}{ Activity } & \multicolumn{1}{c}{ Descriptions } \\
\hline Horticultural activities & Harvesting & Harvesting red lettuce (Lactuca sativa L.) from a garden box $(100 \mathrm{~cm} \times 39 \mathrm{~cm} \times 39 \mathrm{~cm})$ \\
& Planting & Plating peperomia (Peperomia argyreia) in a 10-cm pot \\
& Sowing & Planting radish (Raphanus sativus L.) seeds in a seed tray \\
& Soil-mixing & Using hands to mix soil in the basin \\
Nonhorticultural activities & Ball-playing & Playing ball space $(171 \mathrm{~cm} \times 171 \mathrm{~cm})$. Bouncing basketball. \\
& Math & Solving math problems appropriate for each grade (e.g., $392 \times 47 ; 14+2 \times 13-86 ; 18 \times 5 \div 6 ;$ and $32 \div 11)$ \\
& Video & Watching the animated television show "Pokemon: Catch the carp king!" \\
& Paper-folding & Following the instructions for folding a paper airplane and then folding another paper airplane \\
& Reading & Reading fairy tale books \\
\hline
\end{tabular}



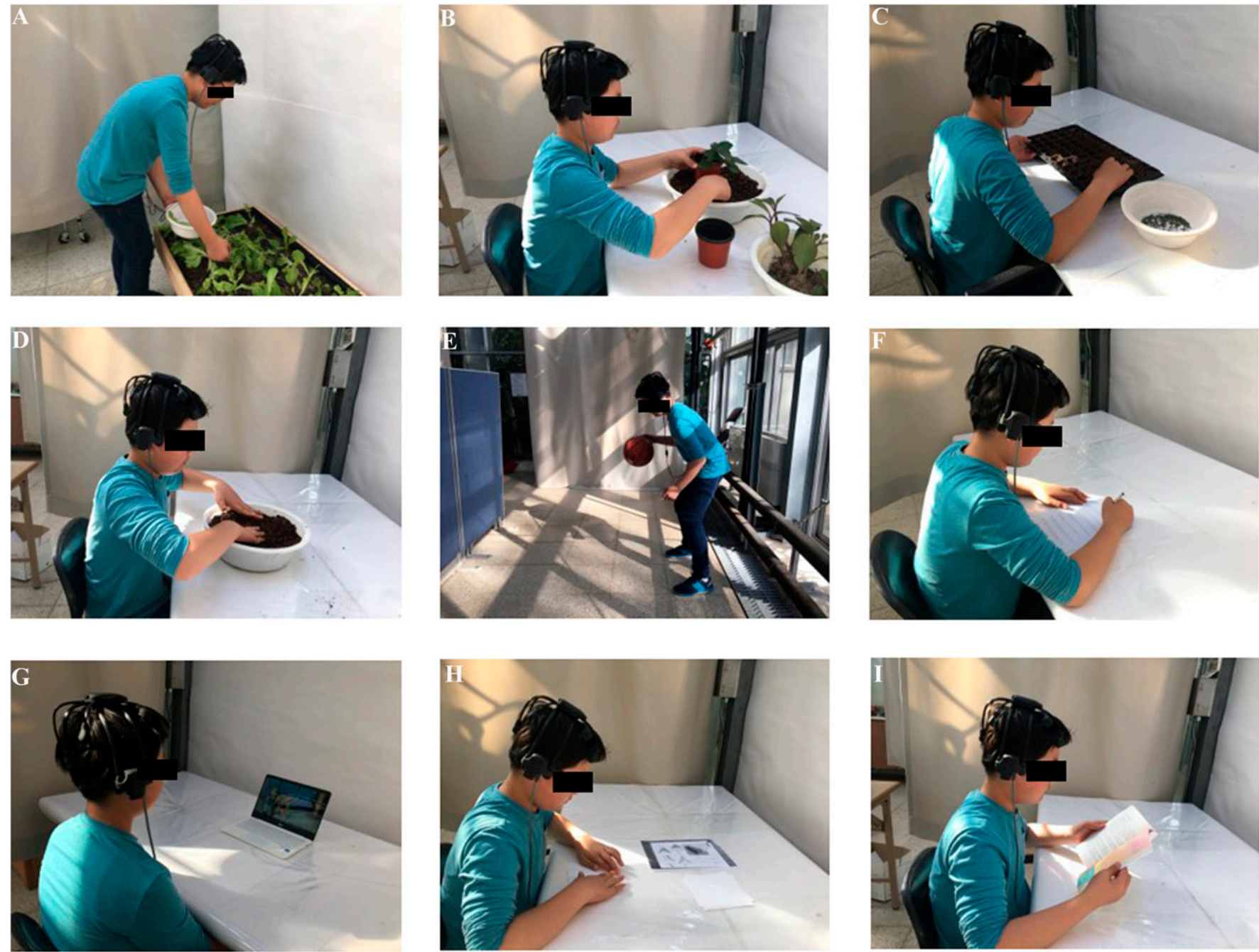

Fig. 2. Experimental performance appearance: (A) harvesting, (B) planting, $(\mathbf{C})$ sowing, (D) soil-mixing, (E) ball-play, (F) math, (G) watching a video, $(\mathbf{H})$ paperfolding, and (I) reading activities.

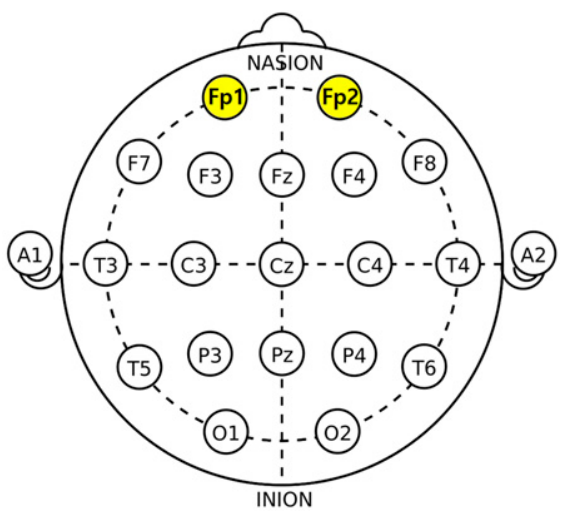

Fig. 3. Electrode locations of the international 1020 system for electroencephalography (EEG).

\section{Results}

Demographic characteristics. There were 30 participants (11 males and 19 females). The average age was $11.3 \pm 1.3$ years. The average weight was $39.8 \pm 11.3 \mathrm{~kg}$. The average height was $143.8 \pm 10.9 \mathrm{~cm}$. The average BMI was $18.9 \pm 3.3 \mathrm{~kg} \cdot \mathrm{m}^{-2}$, which is

Table 2. Descriptive characteristics of participants.

\begin{tabular}{|c|c|}
\hline \multicolumn{2}{|l|}{ Variables } \\
\hline Gender & $\%(\mathrm{~N})$ \\
\hline Male & $36.7(11)$ \\
\hline \multirow[t]{2}{*}{ Female } & $63.3(19)$ \\
\hline & Mean \pm SD \\
\hline Age $(n=30)$ & $11.3 \pm 1.3$ \\
\hline${ }^{ }$Weight $(\mathrm{kg})(\mathrm{n}=29)$ & $39.8 \pm 11.3$ \\
\hline${ }^{\mathrm{y}}$ Height $(\mathrm{cm})(\mathrm{n}=29)$ & $143.8 \pm 10.9$ \\
\hline${ }^{x}$ Body mass index $\left(\mathrm{kg} \cdot \mathrm{m}^{-2}\right)(\mathrm{n}=29)$ & $18.9 \pm 3.3$ \\
\hline
\end{tabular}

within the normal range based on the standards of the Korea Centers for Disease Control and Prevention (Table 2).

$E E G$. When performing the harvesting, video, and reading activities, the participants' RT power spectrum decreased in both prefrontal lobes $(P<0.05)$ (Table 3$)$. Because the theta power is the reverse for attention skills, this result indicated that the participants' concentration increased (Han and Hong, 2017). Moreover, the participants' RMB power spectrum increased in the right prefrontal lobes when performing the har- vesting and ball-play activities. The increase in the RMB power spectrum index signified the activity of the brain. Therefore, this result showed that there was brain activation in participants when performing the harvesting and ball-play activities. The RSMT analysis showed that activity was significantly higher in the right prefrontal lobes of the children when performing the harvesting activity than during other activities. The RSMT was calculated as the beta wave and theta wave, which are indicators of concentration and attention ability (Lubar, 1991; Lubar et al., 
Table 3. Results of the relative theta (RT) power spectrum, relative mid beta (RMB) power spectrum, and ratio of sensorimotor rhythm (SMR) from mid beta to theta (RSMT) according to electroencephalography (EEG).

\begin{tabular}{|c|c|c|c|c|c|c|c|}
\hline \multirow[b]{3}{*}{ EEG } & \multirow[b]{3}{*}{ Activity } & \multicolumn{2}{|c|}{$\mathrm{RT}^{\mathrm{z}}$} & \multicolumn{2}{|c|}{$\mathrm{RMB}^{\mathrm{y}}$} & \multicolumn{2}{|c|}{$\mathrm{RSMT}^{\mathrm{x}}$} \\
\hline & & Fp1 & Fp2 & Fp1 & $\mathrm{Fp} 2$ & Fp1 & Fp2 \\
\hline & & \multicolumn{6}{|c|}{ Mean \pm SD } \\
\hline Total & Harvesting & $0.27 \pm 0.08 \mathrm{~b}^{\mathrm{v}}$ & $0.27 \pm 0.08 \mathrm{~b}$ & $0.09 \pm 0.02 \mathrm{ab}$ & $0.10 \pm 0.04 \mathrm{a}$ & $0.66 \pm 0.28$ & $0.86 \pm 1.10 \mathrm{a}$ \\
\hline \multirow[t]{9}{*}{$(\mathrm{N}=30)$} & Planting & $0.31 \pm 0.08 \mathrm{ab}$ & $0.31 \pm 0.08 \mathrm{ab}$ & $0.09 \pm 0.01 \mathrm{~b}$ & $0.09 \pm 0.01 \mathrm{~b}$ & $0.53 \pm 0.18$ & $0.54 \pm 0.19 b$ \\
\hline & Sowing & $0.30 \pm 0.08 a b$ & $0.30 \pm 0.09 \mathrm{ab}$ & $0.09 \pm 0.02 \mathrm{~b}$ & $0.09 \pm 0.01 \mathrm{~b}$ & $0.57 \pm 0.25$ & $0.54 \pm 0.18 b$ \\
\hline & Soil-mixing & $0.31 \pm 0.08 \mathrm{ab}$ & $0.30 \pm 0.07 \mathrm{ab}$ & $0.09 \pm 0.01 \mathrm{~b}$ & $0.09 \pm 0.01 \mathrm{ab}$ & $0.54 \pm 0.16$ & $0.56 \pm 0.15 b$ \\
\hline & Ball-playing & $0.33 \pm 0.09 \mathrm{a}$ & $0.33 \pm 0.08 \mathrm{a}$ & $0.10 \pm 0.03 \mathrm{a}$ & $0.10 \pm 0.02 \mathrm{a}$ & $0.66 \pm 0.39$ & $0.58 \pm 0.19 b$ \\
\hline & Math & $0.33 \pm 0.08 \mathrm{a}$ & $0.31 \pm 0.07 \mathrm{ab}$ & $0.09 \pm 0.02 \mathrm{~b}$ & $0.09 \pm 0.01 \mathrm{~b}$ & $0.53 \pm 0.21$ & $0.53 \pm 0.16 b$ \\
\hline & Video & $0.28 \pm 0.08 b$ & $0.29 \pm 0.07 \mathrm{~b}$ & $0.09 \pm 0.02 \mathrm{ab}$ & $0.09 \pm 0.01 \mathrm{~b}$ & $0.64 \pm 0.32$ & $0.56 \pm 0.14 b$ \\
\hline & Paper-folding & $0.31 \pm 0.09 \mathrm{ab}$ & $0.30 \pm 0.07 \mathrm{ab}$ & $0.08 \pm 0.01 \mathrm{~b}$ & $0.09 \pm 0.01 \mathrm{~b}$ & $0.52 \pm 0.13$ & $0.54 \pm 0.13 \mathrm{~b}$ \\
\hline & Reading & $0.27 \pm 0.07 \mathrm{~b}$ & $0.27 \pm 0.07 \mathrm{~b}$ & $0.09 \pm 0.01 \mathrm{~b}$ & $0.09 \pm 0.01 \mathrm{~b}$ & $0.60 \pm 0.15$ & $0.59 \pm 0.16 b$ \\
\hline & $P^{\mathrm{w}}$ & $0.026^{*}$ & $0.016^{*}$ & $0.006^{*}$ & $0.015^{*}$ & $0.100^{\mathrm{NS}}$ & $0.042 *$ \\
\hline
\end{tabular}

${ }^{\mathrm{Z}} \mathrm{RT}$ power spectrum was calculated by [theta $(4-8 \mathrm{~Hz})$ power] / [total frequency $(4-50 \mathrm{~Hz})$ power].

${ }^{\mathrm{y}} \mathrm{RMB}$ power spectrum was calculated by [mid beta $(15-20 \mathrm{~Hz})$ power] / [total frequency $(4-50 \mathrm{~Hz})$ power].

${ }^{x}$ RSMT was calculated by [SMR-mid beta $(12-20 \mathrm{~Hz})$ power] / [theta $(4-8 \mathrm{~Hz})$ power].

${ }^{\mathrm{w}}$ Statistical significance as determined using a one-way analysis of variance.

${ }^{v}$ Statistical significance as determined using Duncan's multiple range tests.

$\mathrm{Fp} 1=$ left prefrontal lobe; Fp2 = right prefrontal lobe.

Post hoc analysis: $\mathrm{a}>\mathrm{b}$ according to Duncan's multiple range tests.

Ns, *Nonsignificant or significant at $P<0.05$, respectively.

1995). Therefore, the harvesting activity effectively improved the brain activity and concentration of participants.

Subjective emotion assessment. The results of the SDM survey showed that participants felt more positive when performing horticultural activities than when performing nonhorticultural activities. There was no significant difference in the "being comfortable" item scores, although engaging in horticultural activities led to higher scores than engaging in non-horticultural activities (Fig. 4A). The "being natural" item scores were significantly higher when performing horticultural activities rather than when performing nonhorticultural activities (Fig. 4B), and the "being relaxed" item scores were significantly higher when performing horticultural and reading activities when compared with the other activities (Fig. 4C).

\section{Discussion}

We investigated the effects of horticultural activities and compared them with those of nonhorticultural activities on children by measuring psycho-physiological aspects, such as the EEG and subjective mood conditions. The results showed that during the harvesting activity, the RT power spectrum in the prefrontal lobes of the children significantly decreased, and that the RMB power spectrum and RSMT in the right prefrontal lobe increased significantly compared with other activities. In addition, the SDM results showed that children experienced more psychological stability when performing horticultural activities compared to nonhorticultural activities.

During the harvesting activity, the RT power spectrum index of the participants was significantly decreased and the RMB power spectrum and RSMT indexes were significantly increased in the prefrontal lobes compared to those during other activities (Table 3). The ratio of theta waves and beta waves is related to concentration; furthermore, these waves are subsequently re- lated to mental activity, problem-solving, and decision-making (Sauseng and Klimesch, 2008). They occur naturally during intensive activities, such as deep conversation, sports, and speeches (Hassan et al., 2018a). Therefore, the RSMT and RMB power spectrum indexes are indicators of concentration; therefore, they indicate increased concentration as the theta waves decrease and beta waves increase (Lubar, 1991). An excessively high frequency of theta waves indicates a low level of attention and brain activity (Clarke et al., 2002). For children with attention deficit hyperactivity disorder (ADHD), theta waves are higher than usual (Lazzaro et al., 2001). Lubar (1991) presented the ratio of beta and theta waves as a measure of distinguishing children with and without ADHD. Children with ADHD exhibit increased theta waves in the frontal lobe and decreased frequency of beta waves (Chabot and Serfontein, 1996). Therefore, the increase in the RSMT and RMB power spectrum indexes and the decrease of the RT power spectrum index in the prefrontal lobes during harvesting activity indicated that concentration had improved. This is because children focused on harvesting lettuce during harvesting activities by looking at the color and size of lettuce in the garden, selecting lettuce to be harvested, being careful not to injure other lettuces, and grasping the bottom of the leaf stem to harvest lettuce. In a previous study, Kim et al. (2020) also reported that children's brain activity and attention skills were significantly increased when performing tasks in spaces with plants than in spaces without plants. Igarashi et al. (2015) reported that the prefrontal lobes of participants were activated when observing plants. In addition, Lee et al. (2018b) reported that the RSMT and RMB power spectrum indexes increased after adults engaged in plant-based activities. In this study, we measured and recorded brain waves in the prefrontal lobes of children. The prefrontal lobe is the fastest developing area of a child's brain (Arden and Linford, 2008). Furthermore, the prefrontal lobe is responsible for creativity during cognitive processes and plays a key role in attention, working memory, and goal-oriented behavior (Fuster, 2002). It has also been found to help organize experiences over time (Knight and Grabowecky, 1995). Therefore, it can be said that the frontal lobe is related to cognitive function (Burgess et al., 2007; Sakai and Passingham, 2003).

The brain can be divided into left and right hemispheres. The left hemisphere has linguistic functions and is analytical, slow, and methodical during the processing of single information. The right hemisphere oversees nonverbal functions and is associated with parallel information processing (Cohen, 1973; Xiong et al., 1998). In this study, the results of the EEG during the harvesting activity showed that the RMB power spectrum and RSMT indexes were activated in the right brain hemisphere. This is consistent with previous research that indicated that the right hemisphere is activated in environments with plants and during activities involving plants (Kim et al., 2020; Lee et al., 2018b).

The SDM survey results showed that the items indicating feelings of "being natural" and "being relaxed" had significantly higher scores when performing horticultural activities. This is consistent with a previous study that showed that children exhibited positive emotional states when looking at foliage plants (Oh et al., 2019). Similarly, adults also reported feeling calmer and more comfortable when engaging in plant-based activities (Hassan et al., 2018b). Working with plants has been shown to reduce anxiety (Hassan et al., 2019). Tao et al. (2020) reported that the anxiety index of adults decreased when performing horticultural activities compared with that when performing computer tasks. Shao et al. (2020) compared engagement in horticultural activities and smartphone games performed by children and reported that the parasympathetic nerves increased during horticultural activities. Additionally, skin conductance and sympathetic nerves decreased, thereby reducing tension and stress (Shao et al., 2020). 


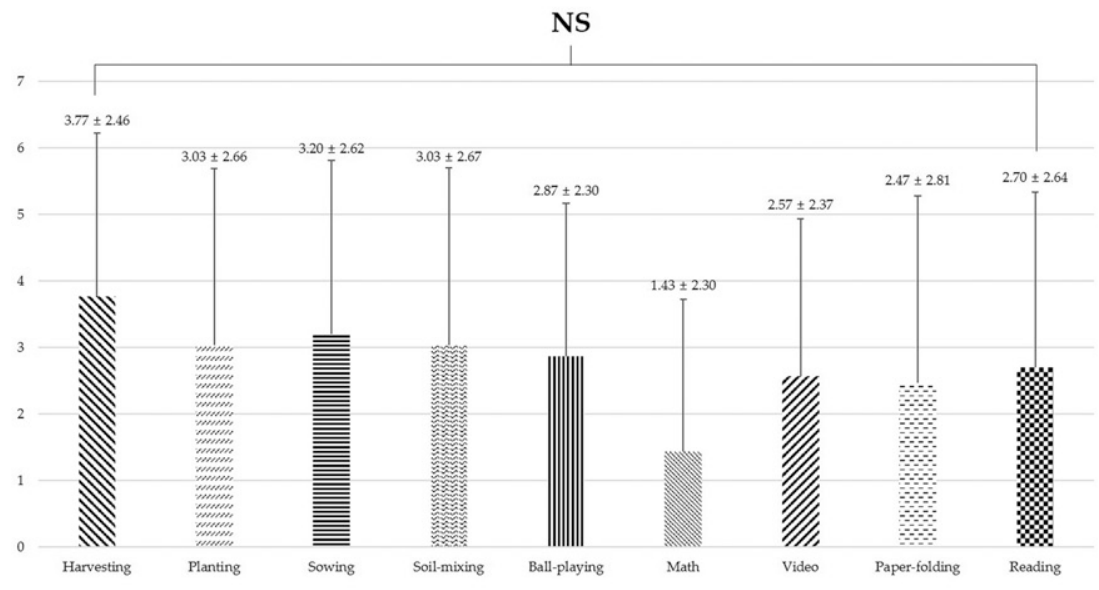

B

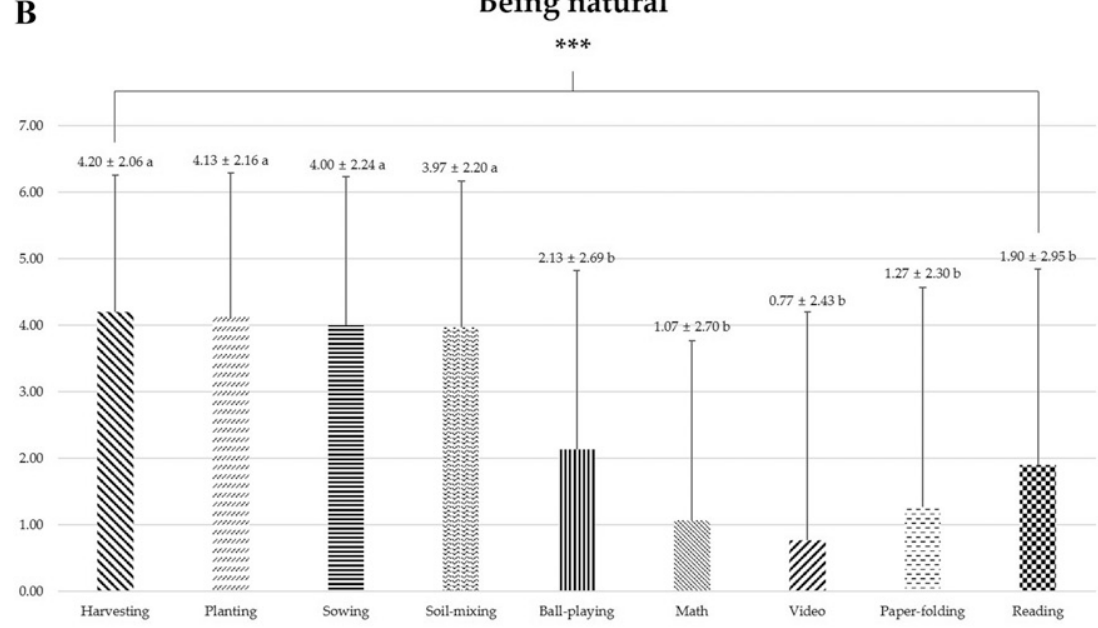

C

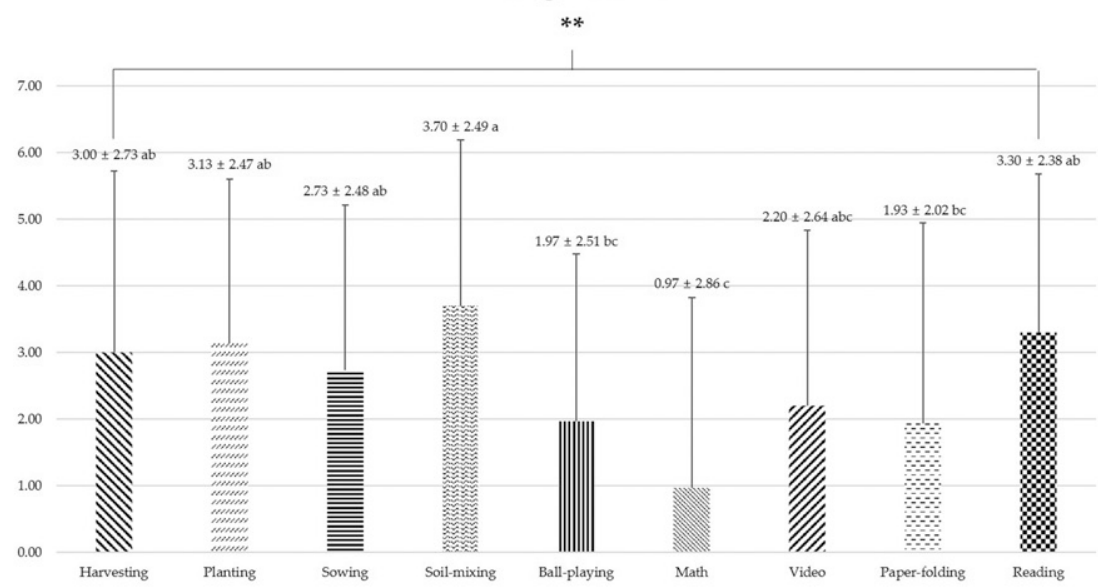

Fig. 4. Comparisons of a semantic differential method (SDM) for each activity. Data are presented as means $\pm \mathrm{SD}(\mathrm{N}=30)$. (A) Being comfortable. (B) Being natural. (C) Being relaxed. NS, nonsignificant. $* * P<0.01$ and $* * * P<0.001$ according to the one-way analysis of variance. Post hoc analysis: $\mathrm{a}>\mathrm{b}>\mathrm{c}$ according to Duncan's multiple range tests.

In conclusion, this study revealed that horticultural activities can increase the concentration in children and stabilize their emotional state. Particularly, the harvesting activity was most effective for improving children's brain activity and concentration. The results of this should increase the number of participants and analyze specific physiological mechanisms, including comparisons between gender and age. It would be interesting to compare the physiological responses of adults with children in future studies. Because this study was conducted in a controlled indoor experimental space, further studies involving psycho-physiological measurements and comparing the effects of horticultural activities in natural spaces are necessary.

\section{Literature Cited}

Arden, J.B. and L. Linford. 2008. Brain-based therapy with children and adolescents: Evidencebased treatment for everyday practice. Wiley, Hoboken, NJ.

Burgess, P.W., I. Dumontheil, and S.J. Gilbert. 2007. The gateway hypothesis of rostral prefrontal cortex (area 10) function. Trends Cogn. Sci. 11:290-298, doi: 10.1016/j.tics.2007.05.004.

Chabot, R.J. and G. Serfontein. 1996. Quantitative electroencephalographic profiles of children with attention deficit disorder. Biol. Psychiatry 40:951963, doi: 10.1016/0006-3223(95)00576-5.

Choi, J.Y., S.A. Park, S.J. Jung, J.Y. Lee, K.C. Son, Y.J. An, and S.W. Lee. 2016. Physiological and psychological responses of humans to the index of greenness of an interior space. Complement. Ther. Med. 28:37-43, doi: 10.1016/j.ctim.2016.08.002.

Choi, S.M. 2015. Fast computation for busy 3 th and 4th graders- multiplication. Essysedu, Seoul, Korea.

Choi, S.M. 2017. Fast computation for busy 3 th and 4th graders-division. Essysedu, Seoul, Korea.

Clarke, A.R., R.J. Barry, R. McCarthy, and M. Selikowitz. 2002. Children with attentiondeficit/hyperactivity disorder and comorbid oppositional defiant disorder: An EEG analysis. Psychiatry Res. 111:181-190, doi: 10.1016/ S0165-1781(02)00137-3.

Cohen, G. 1973. Hemispheric differences in serial versus parallel processing. J. Exp. Psychol. 97:349-356, doi: 10.1037/h0034099.

Fuster, J.M. 2002. Frontal lobe and cognitive development. J. Neurocytol. 31:373-385, doi: 10.1023/A:1024190429920.

Han, A.R., S.A. Park, and B.E. Ahn. 2018. Reduced stress and improved physical functional ability in elderly with mental health problems following a horticultural therapy program. Complement. Ther. Med. 38:19-23, doi: 10.1016/ j.ctim.2018.03.011.

Han, Y.J. and C.H. Hong. 2017. The effects of neurofeedback on the attention in college students with ADHD. J. Kor. Acad. Ind. Coop. Soc. 18:245-255, doi: 10.5762/KAIS.2017.18.1.245.

Hassan, A., C. Qibing, and J. Tao. 2018a. Physiological and psychological effects of gardening activity in older adults. Geriatr. Gerontol. Intl. 18:1147-1152, doi: 10.1111/ggi.13327.

Hassan, A., C. Qibing, J. Tao, L. Bing Yang, L. Nian, S. Li, L.Y. Tng, J.Z. Li, S.G. Ziyue, and M.S. Tahir. 2018b. Effects of plant activity on mental stress in young adults. HortScience 53:104-109, doi: 10.21273/HORTSCI1244717.

Hassan, A., C. Qibing, L. Yinggao, J. Tao, G. Li, M. Jiang, L. Nian, and L. Bing Yang. 2019. Psychological and physiological effects of viewing a money plant by older adults. Brain Behav. 9:e01359, doi: 10.1002/brb3.1359.

Heckman, M.A., J. Weil, and E.G. De Mejia. 2010 Caffeine (1, 3, 7-trimethylxanthine) in foods: A comprehensive review on consumption, functionality, safety, and regulatory matters. 
J. Food Sci. 75:R77-R87, doi: 10.1111/j.17503841.2010.01561.x.

Igarashi, M., C. Song, H. Ikei, and Y. Miyazaki. 2015. Effect of stimulation by foliage plant display images on prefrontal cortex activity: A comparison with stimulation using actual foliage plants. J. Neuroimaging 25:127-130, doi: 10.1111/jon.12078.

Ikei, H., C. Song, M. Igarashi, T. Namekawa, and Y. Miyazaki. 2014. Physiological and psychological relaxing effects of visual stimulation with foliage plants in high school students. Adv. Hort. Sci. 28:111-116. <https://www.jstor.org/ stable/24586807>.

Jasper, H.H. 1958. The ten-twenty electrode system of the international federation. Electroencephalogr. Clin. Neurophysiol. 10:370-375.

Kang, N.Y. and S.M. Choi. 2015. Fast computation for busy 5th and 6th graders-multiplication. Essysedu, Seoul, Korea.

Kang, N.Y. and S.M. Choi. 2017. Fast computation for busy 5th and 6th graders-division. Essysedu, Seoul, Korea.

Kim, D.S. and J.W. Choi. 2001. Electroencephalogram. Koryo Medical, Seoul, Korea.

Kim, S.O., Y.A. Oh, and S.A. Park. 2020. Foliage plants improve concentration and emotional condition of elementary school students performing an intensive assignment. HortScience 55:378-385, doi: 10.21273/HORTSCI1475719.

Knight, R.T. and M. Grabowecky. 1995. Escape from linear time: Prefrontal cortex and conscious experience, p. 1357-1371. In: M.S. Gazzaniga (ed.). The cognitive neurosciences. The MIT Press.

Lazzaro, I., E. Gordon, S. Whitmont, R. Meares, and S. Clarke. 2001. The modulation of late component event related potentials by prestimulus EEG theta activity in ADHD. Intl. J. Neurosci. 107:247-264.

Lee, A.Y., S.O. Kim, G.M. Gim, D.S. Kim, and S.A. Park. 2020. Care farming program for family health: A pilot study with mothers and children. Intl. J. Environ. Res. Public Health 17:27, doi: 10.3390/ijerph17010027.

Lee, M.J., W. Oh, J.S. Jang, and J.Y. Lee. 2018a. A pilot study: Horticulture-related activities significantly reduce stress levels and salivary cortisol concentration of maladjusted elementary school children. Complement. Ther. Med. 37:172-177, doi: 10.1016/j.ctim.2018.01.004.

Lee, S.M., G.M. Gim, S.H. Jeong, S.J. Jeong, K.S. Han, Y. Chea, Y. Jang, S. Lee, and H.J. Jang. 2018b. Analysis of brain waves before and after plant cutting procedure. J. People Plants Environ. 21:379-392, doi: 10.11628/ksppe. 2018.21.5.379.

Lubar, J.F. 1991. Discourse on the development of EEG diagnostics and biofeedback for attentiondeficit/hyperactivity disorders. Biofeedback
Self Regul. 16:201-225, doi: 10.1007/ BF01000016.

Lubar, J.F., M.O. Swartwood, J.N. Swartwood, and P.H. O'Donnell. 1995. Evaluation of the effectiveness of EEG neurofeedback training for ADHD in a clinical setting as measured by changes in TOVA scores, behavioral ratings, and WISC-R performance. Biofeedback Self Regul. 20:83-99, doi: 10.1007/BF01712768.

Miller, E.K. and J.D. Cohen. 2001. An integrative theory of prefrontal cortex function. Annu. Rev. Neurosci. 24:167-202, doi: 10.1146/ annurev.neuro.24.1.167.

Oh, Y.A., A.Y. Lee, K.J. An, and S.A. Park. 2020. Horticultural therapy program for improving emotional well-being of elementary school students: An observational study. Integr. Med. Res. 9:37-41, doi: 10.1016/j.imr.2020.01.007.

Oh, Y.A., S.O. Kim, and S.A. Park. 2019. Real foliage plants as visual stimuli to improve concentration and attention in elementary students. Intl. J. Environ. Res. Public Health 16:796, doi: 10.3390/ijerph16050796.

Olivetti, L., K. Schurr, C. Sherrington, G. Wallbank, P. Pamphlett, M. Mun-San Kwan, and R.D. Herbert. 2007. A novel weight-bearing strengthening program during rehabilitation of older people is feasible and improves standing up more than a non-weight-bearing strengthening program: A randomised trial. Aust. J. Physiother. 53:147-153, doi: 10.1016/S00049514(07)70021-1.

Osgood, C.E., S.J. Suci, and P.H. Tannnenbaum. 1957. The measurement of meaning. Illinois Univ. Press, Champaign, IL.

Park, S.A., A.Y. Lee, J.J. Kim, K.S. Lee, J.M. So, and K.C. Son. 2014b. Electromyographic analysis of upper and lower limb muscles during gardening tasks. Hortic. Sci. Technol. 32:710720, doi: 10.7235 /hort.2014.14059.

Park, S.A., A.Y. Lee, K.S. Lee, and K.C. Son. 2014a. Gardening tasks performed by adults are moderate- to high-intensity physical activities. HortTechnology 24:58-63, doi: 10.21273/ HORTTECH.24.1.58.

Park, S.A., C.R. Song, J.Y. Choi, K.S. Son, and Y. Miyazaki. 2016. Foliage plants cause physiological and psychological relaxation as evidenced by measurements of prefrontal cortex activity and profile of mood states. HortScience 51:1308-1312, doi: 10.21273/ HORTSCI11104-16.

Park, S.A., C.R. Song, Y.A. Oh, Y. Miyazaki, and K.C. Son. 2017. Comparison of physiological and psychological relaxation using measurements of heart rate variability, prefrontal cortex activity, and subjective indexes after completing tasks with and without foliage plants. Intl. J. Environ. Res. Public Health 14:1087, doi: 10.3390/ijerph14091087.

Park, S.A., H.S. Lee, K.S. Lee, K.C. Son, and C.A. Shoemaker. 2013a. The metabolic costs of gardening tasks in children. HortTechnology 23:589-594, doi: 10.21273/HORTTECH.23.5. 589.

Park, S.A., K.S. Lee, and K.C. Son. 2011. Determining exercise intensities of gardening tasks as a physical activity using metabolic equivalents in older adults. HortScience 46:17061710, doi: 10.21273/HORTSCI.46.12.1706.

Park, S.A., S.R. Oh, K.S. Lee, and K.C. Son. 2013b. Electromyographic analysis of upper limb and hand muscles during horticultural activity motions. HortTechnology 23:51-56, doi: 10.21273/HORTTECH.23.1.51.

Park, S.A., S.Y. Son, A.Y. Lee, H.G. Park, W.L. Lee, and C.H. Lee. 2020. Metabolite profiling revealed that a gardening activity program improves cognitive ability correlated with BDNF levels and serotonin metabolism in the elderly. Intl. J. Environ. Res. Public Health 17:541, doi: 10.3390/ijerph17020541.

Relf, D. 1992. Human issues in horticulture. HortTechnology 2:159-171.

Sakai, K. and R.E. Passingham. 2003. Prefrontal interactions reflect future task operations. Nat. Neurosci. 6:75-81, doi: 10.1038/nn987.

Sauseng, P. and W. Klimesch. 2008. What does phase information of oscillatory brain activity tell us about cognitive processes? Neurosci. Biobehav. Rev. 32:1001-1013, doi: 10.1016/ j.neubiorev.2008.03.014.

Shao, Y., M. Elsadek, and B. Liu. 2020. Horticultural activity: Its contribution to stress recovery and wellbeing for children. Intl. J. Environ. Res. Public Health 17:1229, doi: 10.3390/ ijerph17041229.

Sowndhararajan, K., H. Cho, B. Yu, and S. Kim. 2015. Effect of olfactory stimulation of isomeric aroma compounds, (+)-limonene and terpinolene on human electroencephalographic activity. Eur. J. Integr. Med. 7:561-566, doi: 10.1016/j.eujim.2015.08.006.

Tao, J., A. Hassan, C. Qibing, L. Yinggao, G. Li, M. Jiang, D. Li, L. Nian, L. Bing Yang, and Z. Ziqin. 2020. Psychological and physiological relaxation induced by nature-working with ornamental plants. Discrete Dyn. Nat. Soc. 2020:1-7, doi: 10.1155/2020/6784512.

Tarkka, I.M. and M. Hallett. 1990. Cortical topography of premotor and motor potentials preceding self-paced, voluntary movement of dominant and non-dominant hands. Electroencephalogr. Clin. Neurophysiol. 75:36-43, doi: 10.1016/0013-4694(90)90150-I.

Xiong, J., S. Rao, J.H. Gao, M. Woldorff, and P.T. Fox. 1998. Evaluation of hemispheric dominance for language using functional MRI: A comparison with positron emission tomography. Hum. Brain Mapp. 6:42-58, doi: 10.1002/ (SICI)1097-0193(1998)6:1<42:AID-HBM4> 3.0.CO;2-L. 